Research Article

\title{
Risk Assessment and Prevention of Surface Subsidence under Buildings by Cemented Paste Filling and Strip Mining Methods: A Case Study
}

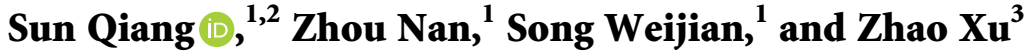 \\ ${ }^{1}$ State Key Laboratory of Coal Resources and Safe Mining, School of Mines, China University of Mining \& Technology, \\ Xuzhou 221116, China \\ ${ }^{2}$ State Key Laboratory for Geomechanics and Deep Underground Engineering, China University of Mining \& Technology, \\ Xuzhou 221116, China \\ ${ }^{3}$ School of Civil, Environmental, and Mining Engineering, The University of Western Australia, Perth 6009, Australia \\ Correspondence should be addressed to Sun Qiang; kkysun@126.com
}

Received 15 March 2021; Accepted 15 May 2021; Published 27 May 2021

Academic Editor: Dezhong Kong

Copyright $\odot 2021$ Sun Qiang et al. This is an open access article distributed under the Creative Commons Attribution License, which permits unrestricted use, distribution, and reproduction in any medium, provided the original work is properly cited.

\begin{abstract}
Intensive and continuous mining of coal resources in China implies their gradual exhaustion, especially in the eastern regions. While some mines face closure, others have to extract residual coal resources under buildings, water bodies, and industrial sites. Thus, safe and efficient mining of the residual coal resources requires innovative techniques, which would account for the particular site's geological conditions. In this study, two schemes of roadway mining with cemented paste backfilling (RMCPB) and strip mining are put forward. After analyzing the type, construction, and protection standard of the buildings, the probability integration method and the prediction model are used to assess the surface subsidence and deformation. The research results show that both schemes can control the surface deformation to a certain extent, but RMCPB combines the advantages of a high coal recovery rate and disposal of gangue waste. According to the surface subsidence predicted and measured data, the RMCPB method can effectively control the surface subsidence, deformation, and buildings' safety. It also yields significant economic and environmental benefits.
\end{abstract}

\section{Introduction}

About half of the world's coal is produced in China, mainly (90\%) by underground mining. Intensive and continuous extraction of coal resources leads to their gradual exhaustion in east-central densely populated areas of China [1-3]. Furthermore, environmental problems in coal mining, including surface subsidence and solid waste accumulation affected by multiple mining, become very topical [4-6]. Statistics indicate that the subsiding areas induced by caving coal mining annually amount to about $40,000 \mathrm{hm}^{2}$, resulting in the annual financial losses of about 300 million USD. At present, the total area of coal mining-induced surface subsidence in China has reached $700,000 \mathrm{hm}^{2}$ [7]. On the other hand, waste gangue is produced and accumulated on the ground, occupying significant land resources and polluting the environment $[8,9]$. An effective technique for controlling surface subsidence with simultaneous disposing of the resulting solid waste in coal mining is urgently required to mitigate these problems.

Several studies have been conducted to substantiate and develop such techniques. Yu et al. [10] examined the rationality of the strip mining scheme with a large mining depth under dense buildings and analyzed the reasonable range of strip mining and reserved widths. The Wilson theory and FLAC numerical simulation were used to predict the surface movement and deformation under different mining conditions. The reasonable strip mining width was assessed at $120 \mathrm{~m}$, ensuring the safe and economic mining under the surface village buildings. Zhang et al. [11] analyzed 
the risk assessment and prevention of surface subsidence in deep multiple coal seam mining under dense above-ground buildings using numerical simulation and surface subsidence prediction methods in solid backfill mining. Teng et al. [12] studied the surface subsidence characteristics of grout injection into overburden on the side of a stopping line (SSL) of a long wall via in situ monitoring, whereas areas with grouting were compared with those without it. Based on the key strata theory and numerical simulation experiment, Liu et al. [13] studied the space-time relationship between the breaking of key strata and surface subsidence in high water filling, analyzed the main factors affecting the surface subsidence, and evaluated the control effect of surface subsidence in high water filling. The above research studies promoted the green and efficient mining of coal resources. However, because of the difference between the backfill materials and filling costs, a rapid and economic backfill coal mining method suitable for residual coal resources in smalland medium-sized coal mines has not been proposed and widely implemented yet.

Alternatively, the cemented paste backfilling (CPB) technology, which offered both economic and environmental benefits, has been used extensively in China's underground mines $[14,15]$. Besides, CPB provides ground and wall support, which also facilitates mine waste disposal. Thus, it limits the likelihood of caving and prevents subsidence. Moreover, CPB technology significantly improves underground mine operations' safety and increases productivity. Therefore, it is now considered a standard practice in mining operations worldwide. In this study, the mining geological conditions, type, construction, and buildings' protection standards are analyzed. Then, two schemes of RMCPB and strip mining methods are discussed in detail. The prediction model of the probability integration method is proposed to study the surface subsidence and deformation during the mining. The surface subsidence predictions and field measurements are compared, and conclusions on the most lucrative mining scheme are drawn.

\section{Description of the Area under Study}

2.1. Mining Geological Conditions. The coal mine studied in this study belongs to the Xinwen Mining Group Co., Ltd., and is located in Shandong Province of China. The construction of the mine began in November 1971 and was put into operation in July 1982. The mine's design capacity is 0.45 million tons per year, and the approved production capacity was 0.9 million tons per year in 2006. The mine design adopts vertical and inclined shaft, multilevel, main crosscut, horizontal main roadway, and mixed development of up and downhills. There are three mining areas in the mine design: the first mining area, the fourth mining area, and the sixth mining area. The mining method adopts the strike longwall retreating mining method, both caving and filling methods to manage the roof. Besides, the strip mining method is adopted for special blocks, such as coal resources under buildings. No. 4 coal seam is the main mining coal seam, which has been mined out except the coal resources under the industrial square and buildings. The coal resources of the safety coal pillar at a depth of $300 \mathrm{~m}$ below the industry square amount to 1.29 million tons, including the main and auxiliary shaft coal pillars resourced of 0.65 million tons. Coal resources under buildings in the Western area are about 0.50 million tons.

According to the geological report on the mine, No. 4 coal seam is the main mineable coal seam with black-colored, brittle coal developed in endogenous fractures. The average thickness of the coal seam is $2.0 \mathrm{~m}$. The fracture surface has usually a ladder-and-shell pattern. The coal petrography is mainly composed of bright coal and vitrinite, and the coal rock type belongs to the semibright type. Its bulk density is 1.37 , hardness is $2.5 \sim 3.0$, and medium ash is low sulfur, while the ash melting point is quite high. The main roof is grayish-white medium sandstone with a thickness of about $15 \mathrm{~m}$. The composition is mainly quartz, followed by feldspar. The intermittent oblique bedding is developed and hard. The upper part is intercalated with a thin layer of siltstone, interbedded with developed fractures, and partially filled with calcite. The immediate floor is light gray siltstone with a thickness of about $8 \mathrm{~m}$. The roof is rich in plant fossils, and the middle part is intercalated with a thin layer of carbonaceous shale or gray clay shale. The main floor is light gray, fine-grained sandstone with a thickness of $3 \mathrm{~m}$. The composition is mainly quartz, followed by feldspar and calcareous (relatively hard) cementation. The distribution of surface buildings and generalized stratigraphic column in the study area are shown in Figure 1.

\subsection{Antideformation Capacity and Reinforcement Criteria.} The investigated mining area is located south of the industry square; the mining area is about 0.21 square kilometers. The investigation results of surface buildings showed that they varied in dimensions, layout, and structure. The buildings mainly included a village, a hospital, a coal washery, and a workshop with brick and timber structures of a certain antideformation ability, as shown in Figure 2. The protection requirements of surface buildings in this area were not high, so strip mining was adopted in the original design. According to the four-level classification of damage to surface brick-concrete structures of the Chinese State Bureau of Coal Industry (2000) given in Table 1, the area's building damage was controlled within level I (negligible damage, no repair required), and the maximum subsidence was controlled within $300 \mathrm{~mm}$.

\section{Mining Scheme and Surface Subsidence Prediction}

3.1. Mining Scheme Design. According to the distribution characteristics of surface buildings and antideformation capacity in the studied mining area, the strip mining and backfilling mining methods were designed. In the first scheme, the studied mining area was subdivided into four strip mining faces: 1402, 1404, 1406, and 1408, in which the caving mining method is adopted. The width of mining faces and safety coal pillars was about $40 \mathrm{~m}$. In the second scheme, the studied mining area was subdivided into eight backfill mining faces, 1401 1408, in which the roadway 

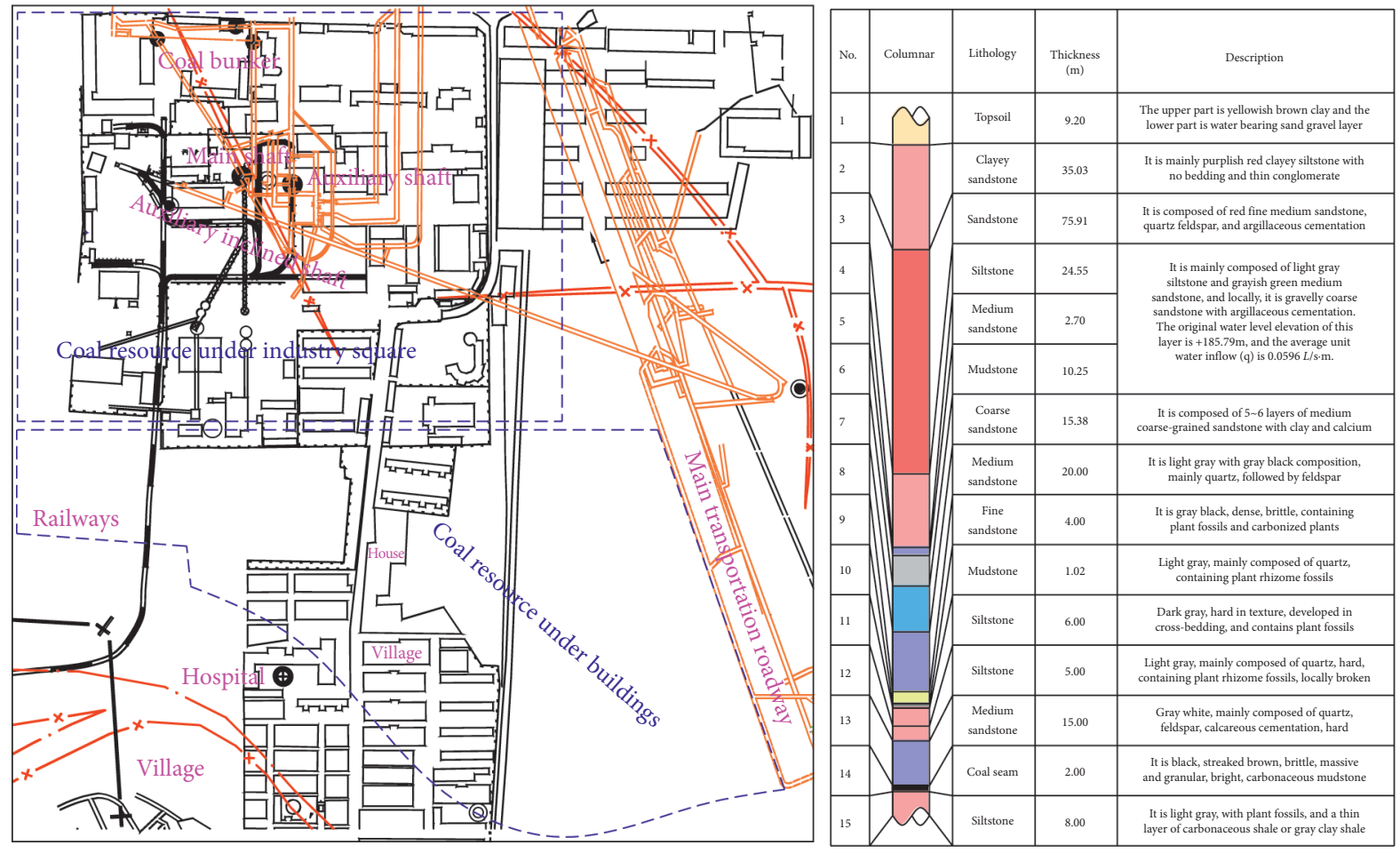

FIgURE 1: Distribution of surface buildings and generalized stratigraphic column in the study area.

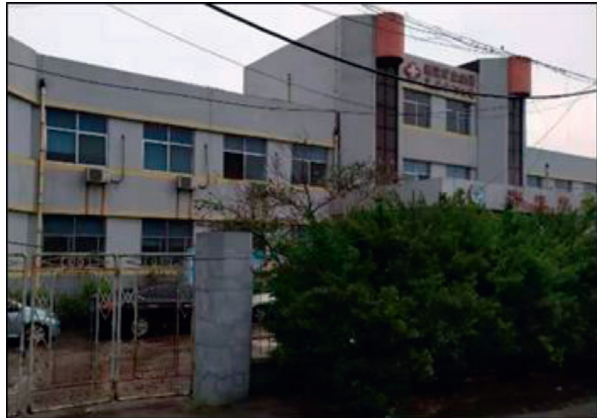

(a)

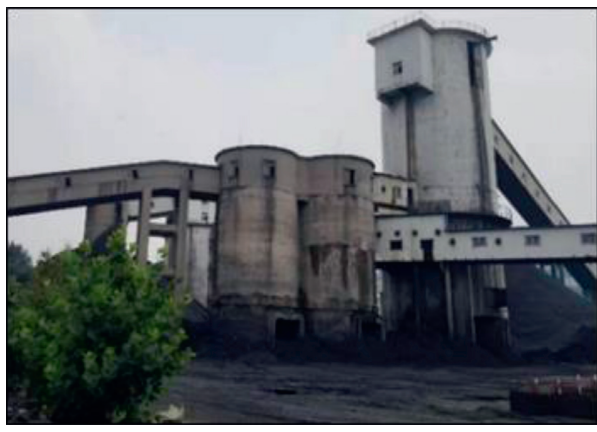

(c)

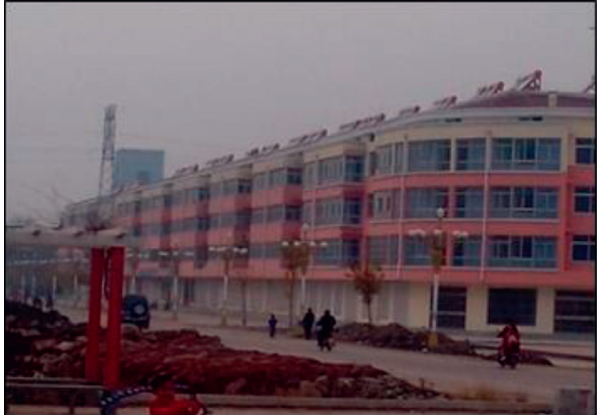

(b)

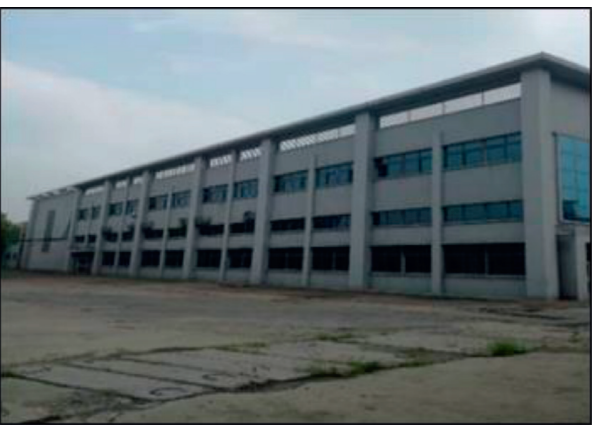

(d)

FIgURe 2: Photos of above-ground buildings: (a) hospital, (b) village, (c) coal washery, and (d) workshop.

mining with the cemented paste backfilling (RMCPB) method was adopted. For the first mining method, it is relatively mature with low investment cost, but less coal production. The second method needs to increase the backfilling equipment, the investment cost is relatively high, but the coal production is large, and the solid waste products of the mine can be treated at the same time. The width of RMCPB faces was about $40 \mathrm{~m}$. The roadway layouts of the mining face for both methods are shown in Figure 3. 
TABLE 1: Classification of damage to surface brick-concrete structures [16].

\begin{tabular}{lccccc}
\hline Damage level & $\begin{array}{c}\text { Surface deformations } \\
\text { Horizontal deformation } \\
(\mathrm{mm} / \mathrm{m})\end{array}$ & $\begin{array}{c}\text { Curvatures } \\
\left(\mathrm{mm} / \mathrm{m}^{2}\right)\end{array}$ & Inclinations $(\mathrm{mm} / \mathrm{m})$ & Classification & Structural processing \\
\hline I & $\leq 2.0$ & $\leq 0.2$ & $\leq 3.0$ & Negligible damage & No repair \\
II & $\leq 4.0$ & $\leq 0.4$ & $\leq 6.0$ & Very slight damage & Light repair \\
III & $\leq 6.0$ & $\leq 0.6$ & $\leq 10.0$ & Slight damage & Minor repair \\
IV & $>6.0$ & $>0.6$ & $>10.0$ & Severe damage & Medium repair \\
& & & Very severe damage & Demolition and construction \\
\hline
\end{tabular}

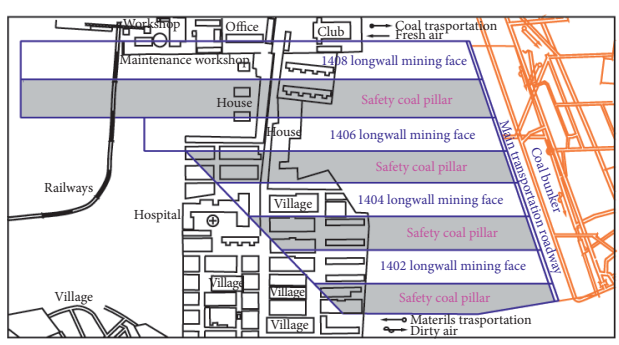

(a)

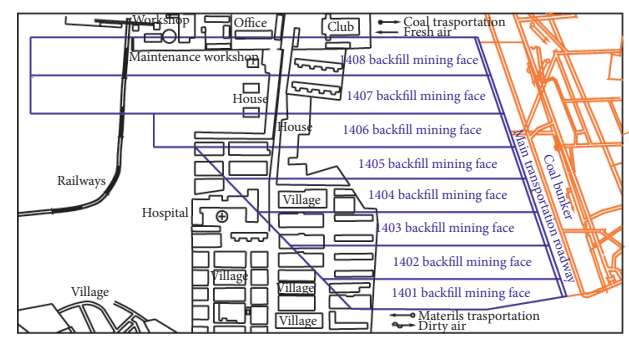

(b)

Figure 3: Roadway layouts of mining face for two mining methods: (a) strip mining; (b) RMCPB.

Based on the conventional coal mining method's production system, RMCPB is a backfill mining method with circulation operation of "driving roadway for mining and filling one by one" [17-19]. The principle is to excavate the crossheading between two roadways of a fully mechanized road header's working face. The gangue and fly ash are used as the main filling materials. Under the action of cementitious materials, high-concentration slurry without dehydration treatment is prepared according to a certain mix proportion, and the filling material is transported underground via a filling pump and a pipeline. The related equipment is mainly composed of coal mining, filling, and transportation subsystems. The first one includes a fully mechanized road header and a local ventilator. Filling equipment contains a filling pump, a crusher, a vibrating screen, a mixer, a batching machine, and a filling pipeline. The transportation equipment mainly includes a scraper conveyor and a belt conveyor. The preparation process of RMCPB material includes four steps: dry material preparation, filling materials mixing, mix and stir with water, and pumping of filling material. In this study, gangue accounts for $80 \%$, cement and fly ash $20 \%$, and the compressive strength of the material can reach $2.0 \mathrm{MPa}$ in 7 days and $5.0 \mathrm{MPa}$ in 28 days. Hbmg 110/14-500 backfilling industrial pump was selected according to the backfilling distance. The technical principle and filling process of RMCPB are shown in Figure 4.

3.2. Surface Subsidence Prediction. The probability integral method was adopted in this study to predict surface movement and deformation with the two coal mining methods according to the principles of surface subsidence control based on the equivalent mining height (EMH) theory [20-23]. In this model, the surface movement and deformation were calculated by the following equations:

$$
\begin{aligned}
& W(x)=\frac{M q \cos a(1-\varphi)}{2}\left[\operatorname{erf}\left(\frac{\sqrt{\pi}}{r} x\right)+1\right], \\
& U(x)=b M q \cos a(1-\varphi) e^{-\left(\pi x^{2} / r^{2}\right)}, \\
& i(x)=\frac{M q \cos a(1-\varphi)}{r} e^{-\left(\pi x^{2} / r^{2}\right)}, \\
& \mathcal{E}(x)=-2 \pi b \frac{M q \cos a(1-\varphi)}{r^{2}} x e^{-\left(\pi x^{2} / r^{2}\right)}, \\
& k(x)=-2 \pi \frac{M q \cos a(1-\varphi)}{r^{3}} x e^{-\left(\pi x^{2} / r^{2}\right)},
\end{aligned}
$$

where $W(x)$ is the subsidence, $U(x)$ is the horizontal movement, $i(x)$ is the inclination, $\varepsilon(x)$ is the horizontal deformation, $k(x)$ is the curvature deformation, $M$ is the mining height, $q$ is the surface subsidence coefficient, $b$ is the horizontal movement coefficient, $a$ is the angle of inclination of the coal seam, and $\varphi$ is the backfill materials' compression ratio. The above formulas also feature $r=H /$ $\tan \beta$, where $r$ is the radius of influence, $H$ is the mining depth, and $\tan \beta$ is the tangent of the main angle of influence. In actual engineering, the surface subsidence coefficient $q$ is set as $0.85, b=0.31, \tan \beta=2.0, a=0$, and $\varphi=90 \%$.

The Surfer of Golden Software and CAD commercial packages were used to process the surface deformation data. The horizontal surface deformation, inclination, curvature, horizontal movement, and subsidence along the north-south and east-west lines in RMCPB are shown in Figures 5 9. The 


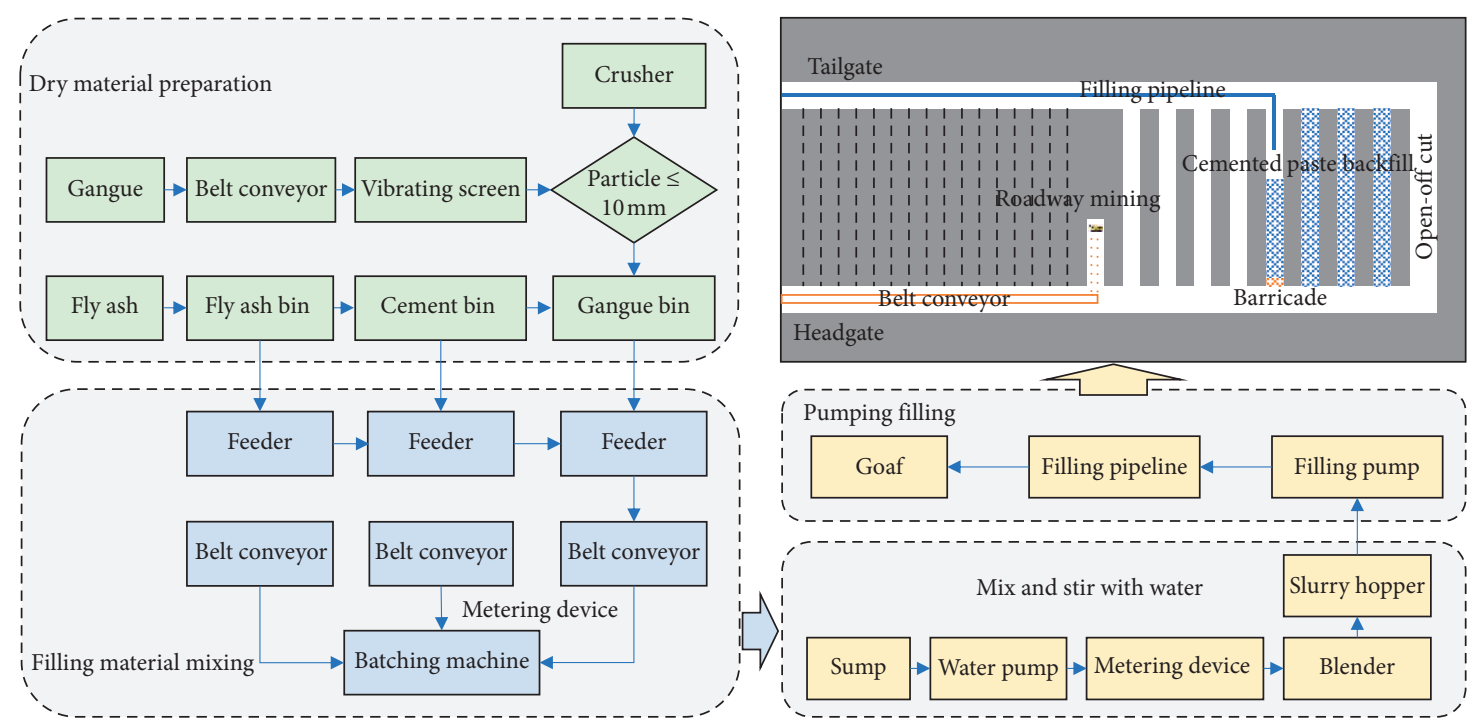

FIGURE 4: Technical principle and the filling process of RMCPB.

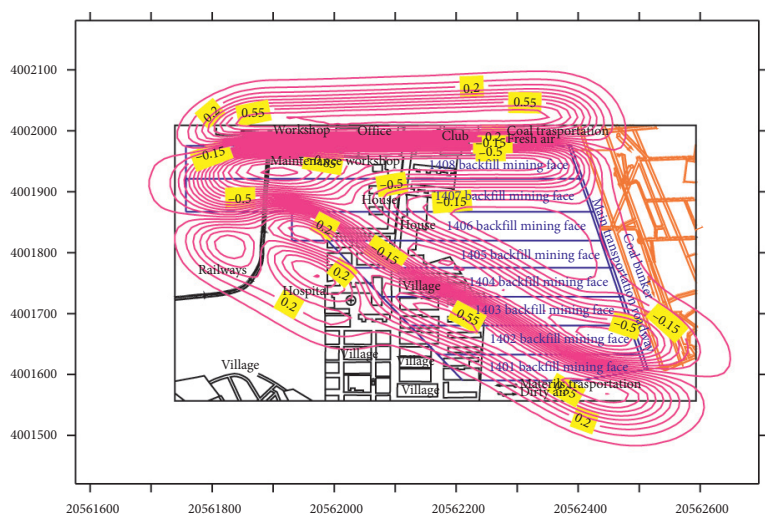

(a)

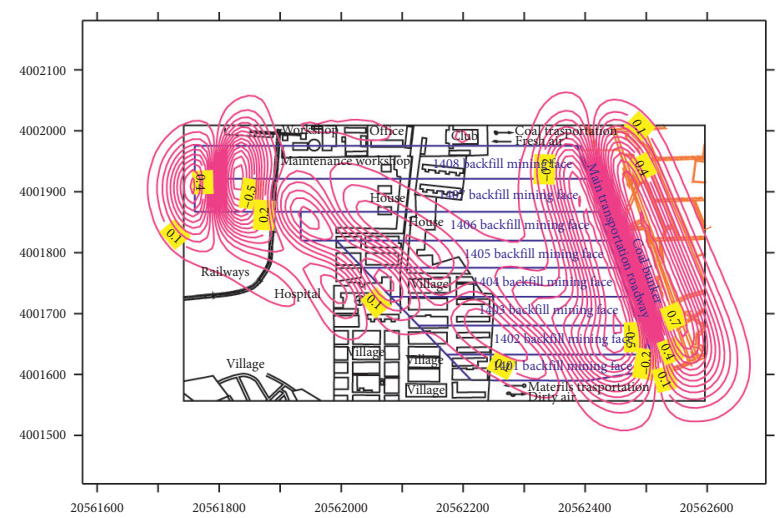

(b)

FIGURE 5: Contour map of horizontal surface deformation in RMCPB.

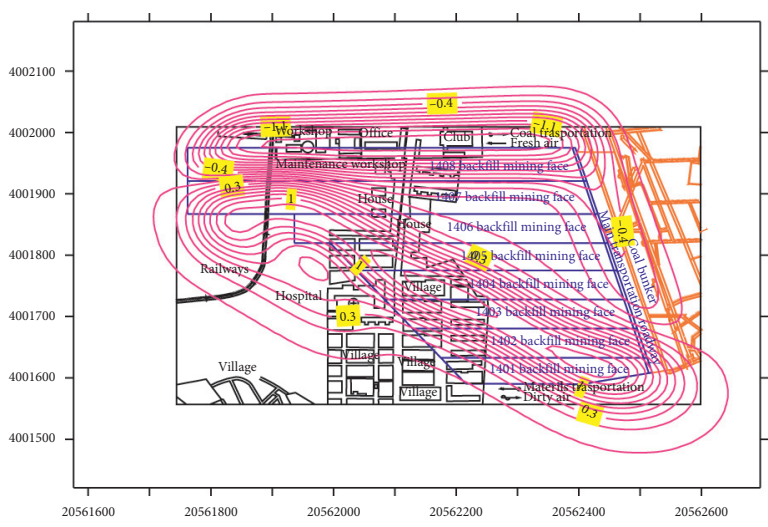

(a)

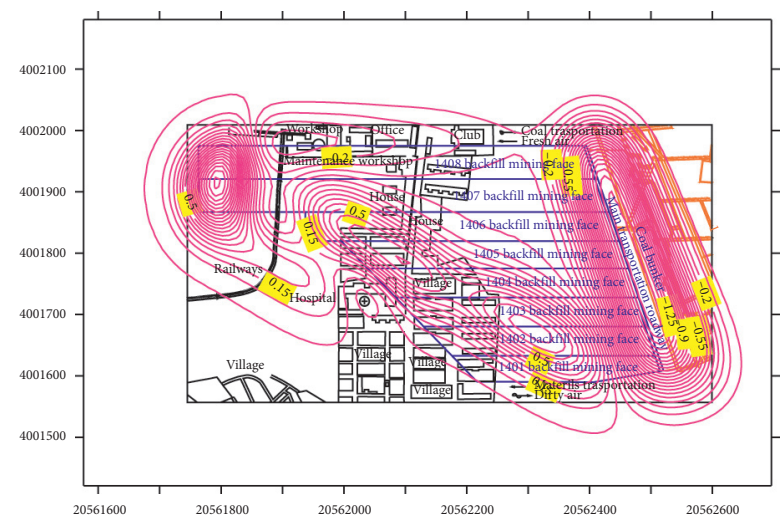

(b)

FIGURE 6: Contour map of surface inclination in RMCPB.

surface movement and deformation extremum is given in Table 2.

Similarly, the horizontal surface deformation, inclination, curvature, horizontal movement, and subsidence, along the north-south and east-west lines in strip mining were derived and are shown in Figures 10 14. The surface movement and deformation extrema are listed in Table 3. 


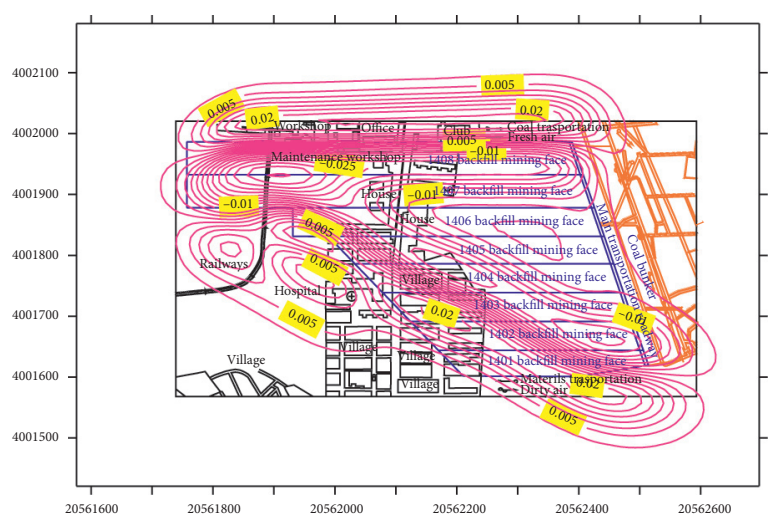

(a)

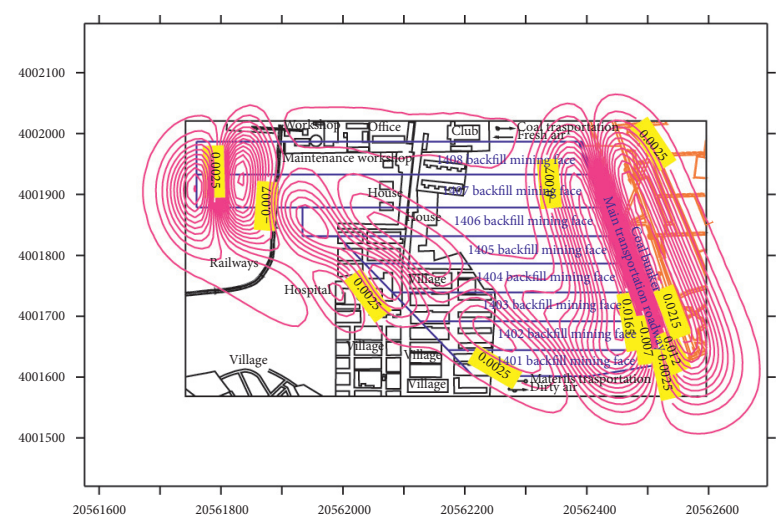

(b)

Figure 7: Contour map of surface curvature in RMCPB.

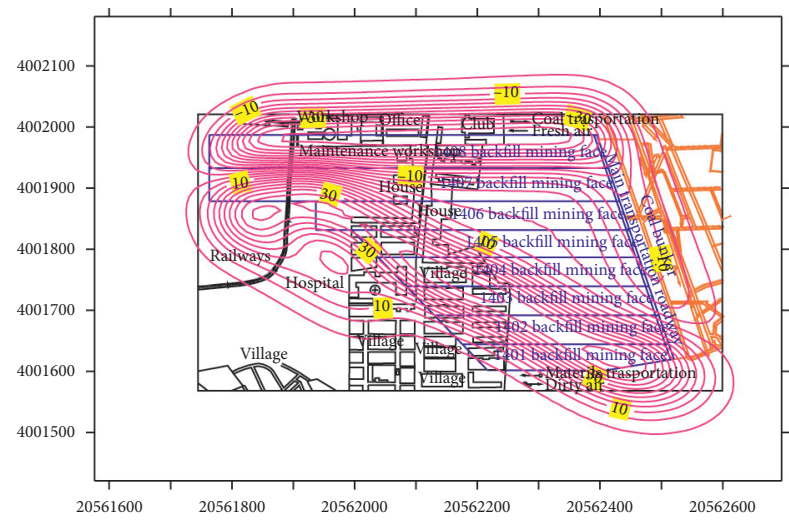

(a)

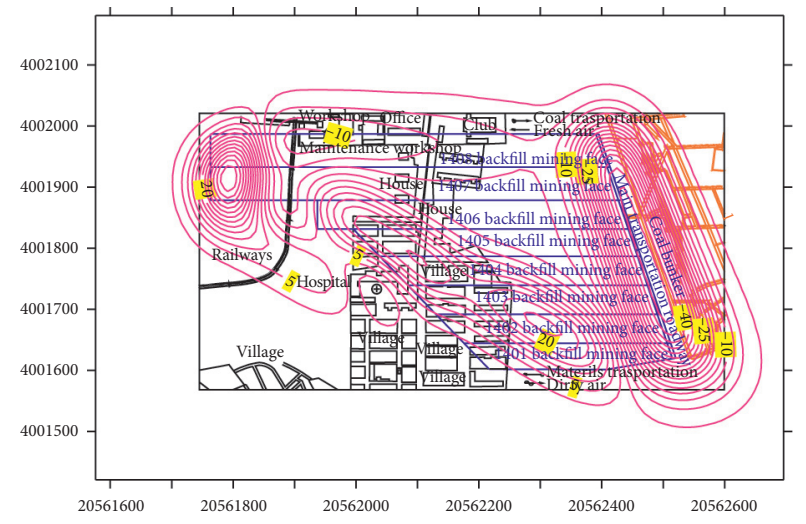

(b)

Figure 8: Contour map of horizontal surface movement in RMCPB.

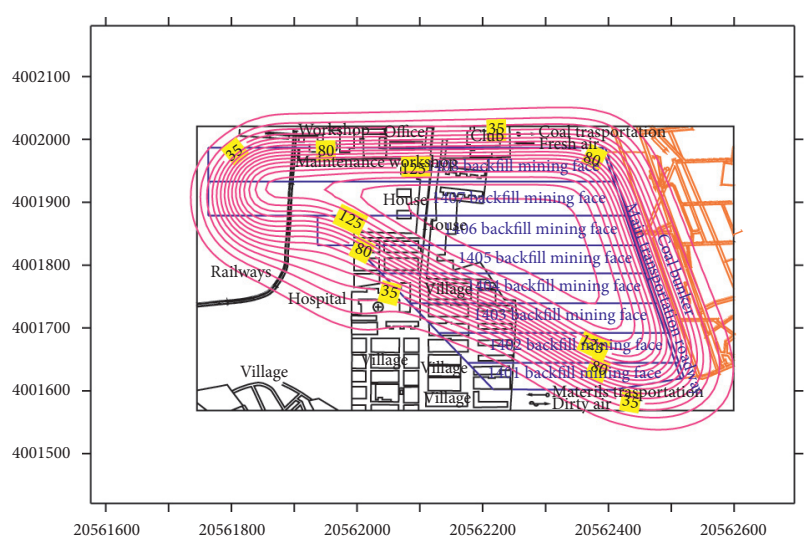

FIGURE 9: Contour map of surface subsidence in RMCPB.

It can be seen from Figures 5-9 and Table 3 that the maximum subsidence of the surface above the studied mining area with RMCPB was $170 \mathrm{~mm}$; the maximum horizontal movement of the ground surface along the southnorth line was $55 \mathrm{~mm}$ and that along the east-west one was $50 \mathrm{~mm}$. The maximum horizontal deformation of the surface in the south-north line was $0.8 \mathrm{~mm} / \mathrm{m}$ and that in the eastwest one was $1.2 \mathrm{~mm} / \mathrm{m}$. The maximum inclination along the south-north and east-west lines was 1.6 and $1.8 \mathrm{~mm} / \mathrm{m}$, respectively. The maximum curvature along the south-north and east-west lines was 0.03 and $0.04 \mathrm{~mm} / \mathrm{m}^{2}$, respectively.

Figures 10-14 and Table 4 show that the maximum subsidence of the surface above the studied mining area with strip mining was $230 \mathrm{~mm}$; the maximum horizontal movement of the ground surface along the south-north line was $100 \mathrm{~mm}$ and that along the east-west one was $110 \mathrm{~mm}$. The maximum horizontal deformations of the surface along the south-north and east-west lines were 0.38 and $0.40 \mathrm{~mm} /$ $\mathrm{m}$, respectively. The maximum inclinations along the southnorth and east-west lines were identical and equal to $0.35 \mathrm{~mm} / \mathrm{m}$. The maximum curvatures along the southnorth and east-west lines were 0.03 and $0.04 \mathrm{~mm} / \mathrm{m}^{2}$, respectively.

From the above analysis, the extreme values of surface deformation under both mining schemes fell within the level I of damage to surface buildings. Still, the overall disturbance degree and mining influence area of RMCPB was weak, being mainly reflected in the subsidence and horizontal movement. In strip mining, the subsidence and horizontal 
TABLE 2: Surface movement and deformation extrema in RMCPB.

\begin{tabular}{|c|c|c|c|c|c|c|c|c|}
\hline \multirow[t]{2}{*}{ Subsidence (mm) } & \multicolumn{2}{|c|}{$\begin{array}{l}\text { Horizontal movement } \\
(\mathrm{mm})\end{array}$} & \multicolumn{2}{|c|}{$\begin{array}{l}\text { Horizontal deformation } \\
\qquad(\mathrm{mm} / \mathrm{m})\end{array}$} & \multicolumn{2}{|c|}{$\begin{array}{l}\text { Inclination deformation } \\
\qquad(\mathrm{mm} / \mathrm{m})\end{array}$} & \multicolumn{2}{|c|}{ Curvature $\left(\mathrm{mm} / \mathrm{m}^{2}\right)$} \\
\hline & South-north & East-west & South-north & East-west & South-north & East-west & South-north & East-west \\
\hline 170 & 55 & 50 & 0.8 & 1.2 & 1.6 & 1.8 & 0.03 & 0.04 \\
\hline
\end{tabular}

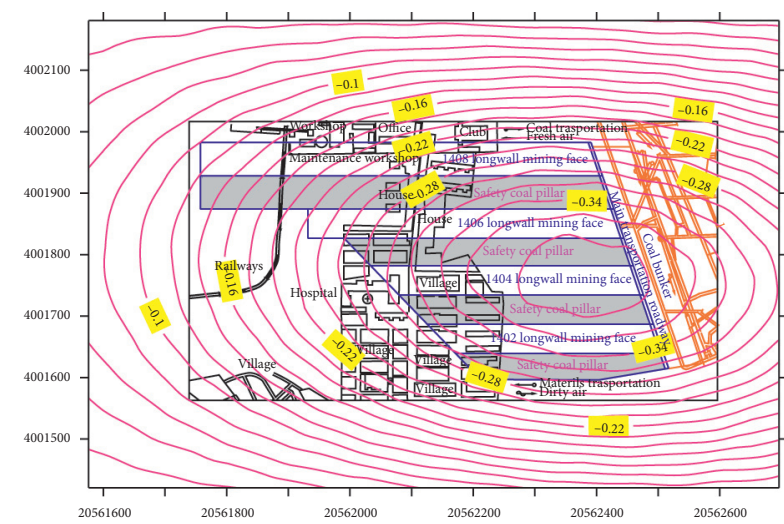

(a)

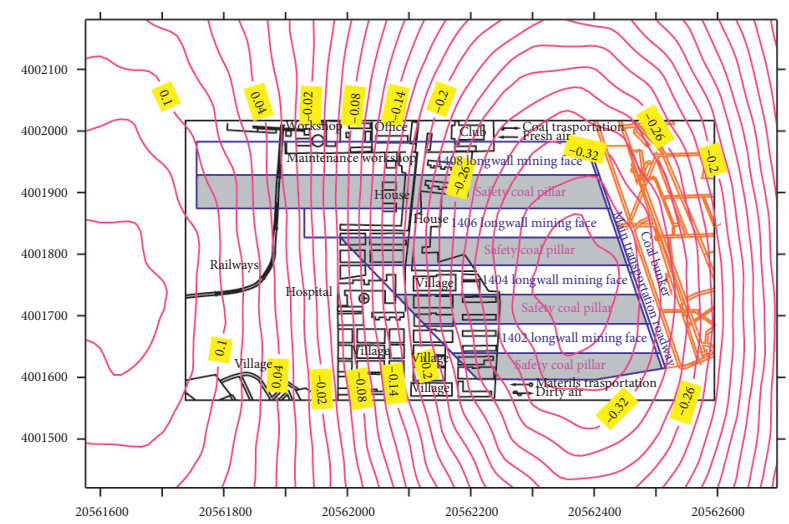

(b)

Figure 10: Contour map of horizontal surface deformation in strip mining.

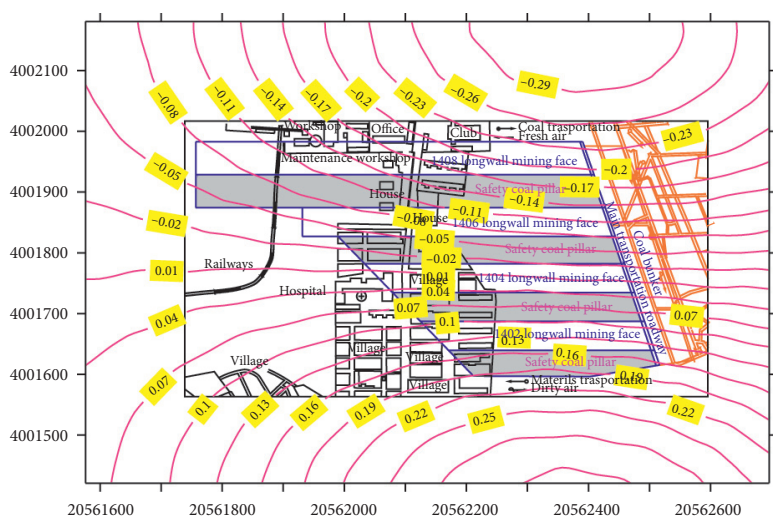

(a)

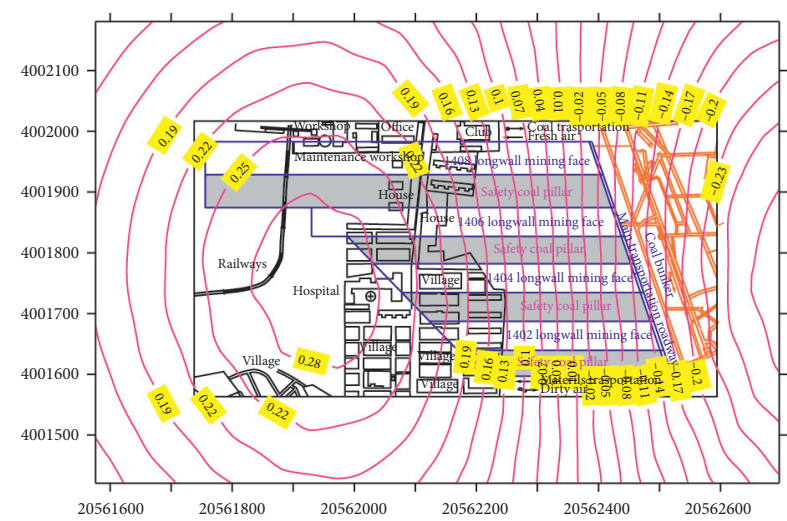

(b)

FIGURE 11: Contour map of surface inclination in strip mining.

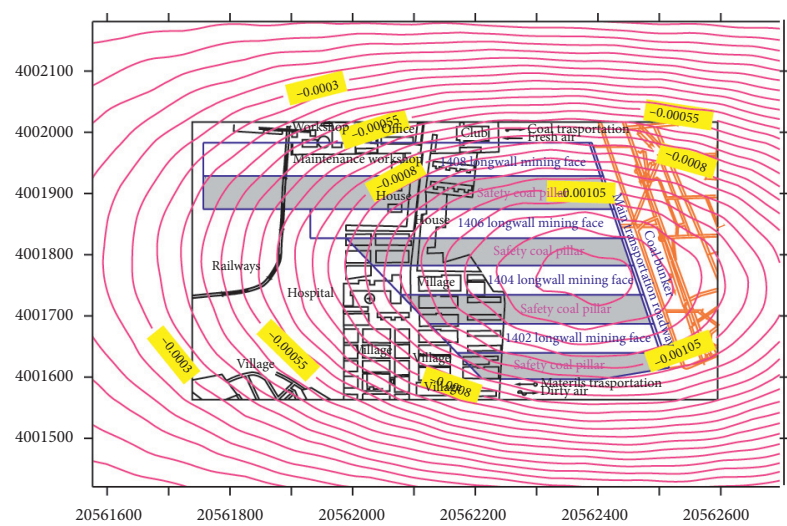

(a)

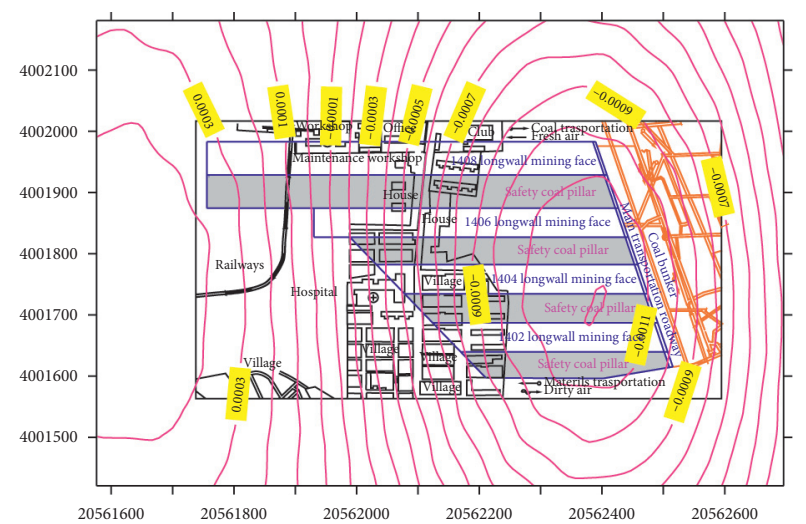

(b)

Figure 12: Contour map of surface curvature in strip mining. 


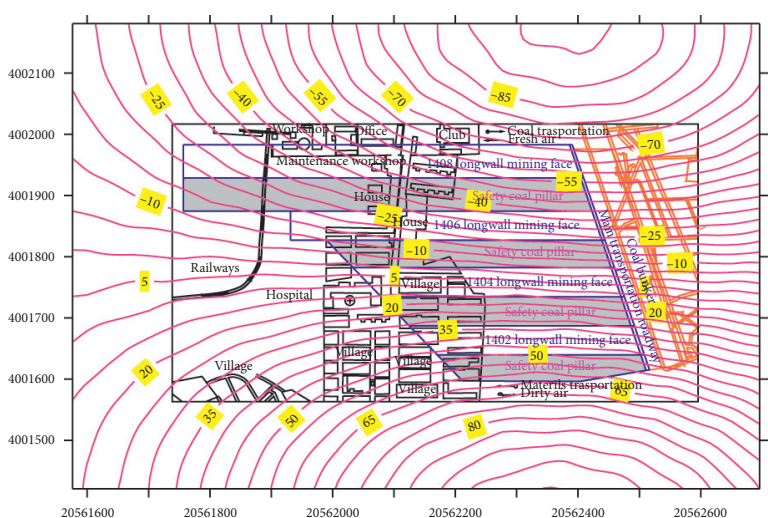

(a)

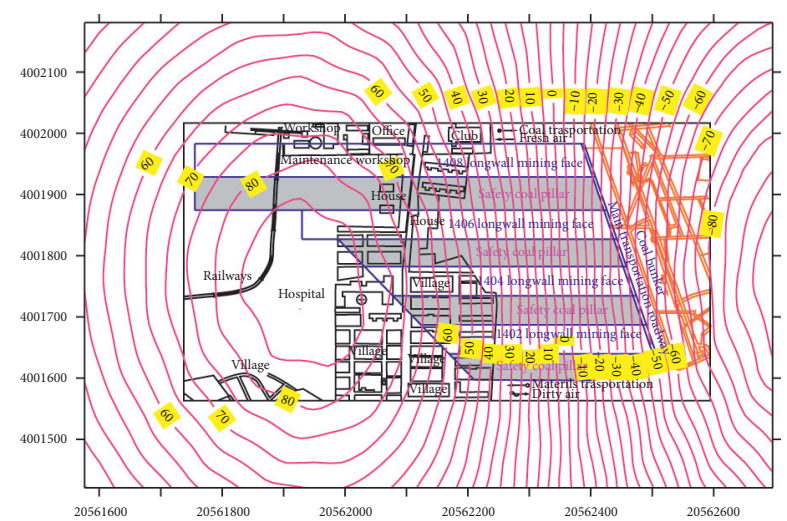

(b)

FIGURE 13: Contour map of horizontal surface movement in strip mining.

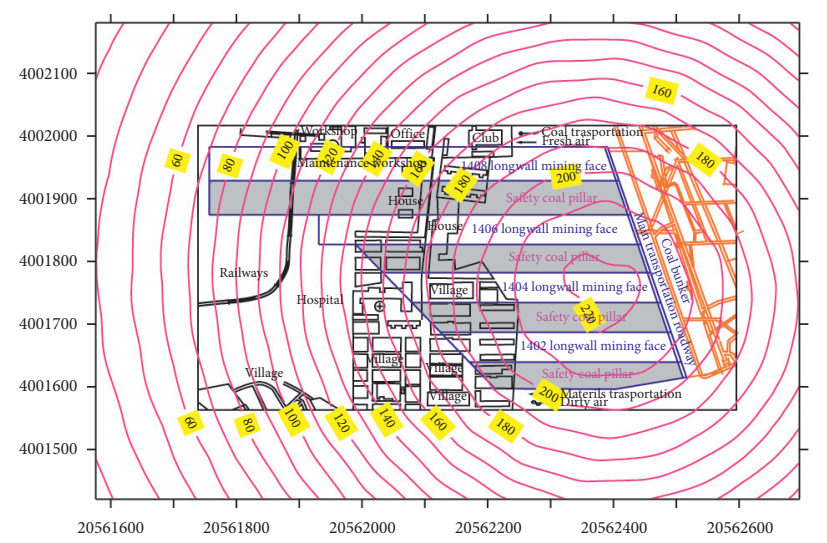

Figure 14: Contour map of surface subsidence in strip mining.

TABLE 3: Surface movement and deformation extremum in strip mining.

\begin{tabular}{lcccccccc}
\hline Subsidence $(\mathrm{mm})$ & $\begin{array}{c}\text { Horizontal movement } \\
(\mathrm{mm})\end{array}$ & \multicolumn{2}{c}{$\begin{array}{c}\text { Horizontal deformation } \\
(\mathrm{mm} / \mathrm{m})\end{array}$} & \multicolumn{2}{c}{$\begin{array}{c}\text { Inclination deformation } \\
(\mathrm{mm} / \mathrm{m})\end{array}$} & \multicolumn{2}{c}{ Curvature $\left(\mathrm{mm} / \mathrm{m}^{2}\right)$} \\
& South-north & East-west & South-north & East-west & South-north & East-west & South-north & East-west \\
\hline 230 & 100 & 110 & 0.38 & 0.40 & 0.35 & 0.35 & 0.03 & 0.04 \\
\hline
\end{tabular}

movement extreme values were relatively high, and the mining influence area was large. Still, the horizontal surface and inclined deformations were relatively small due to the protection of coal pillars. After coal mining in this area, the buildings and structures within the influence range of surface deformation were not affected. The main workshop, office building, clothing factory, and other buildings located south to the industrial square and at the edge of the mining area had different degrees of movement and deformation. Still, the extreme values of inclined and horizontal deformations were within the damage level I, which met the requirements of building antideformation capacity and reinforcement criteria.

\section{Discussion}

The field measurements under strip mining in the eastern mining area show that for the longwall mining face width of
$40 \mathrm{~m}$, and protective coal pillars' width of $40 \mathrm{~m}$, the maximum subsidence was $440 \mathrm{~mm}$, the maximum surface horizontal deformation was $-1.85 \mathrm{~mm} / \mathrm{m}$, and the maximum inclination was $-3.5 \mathrm{~mm} / \mathrm{m}$. Meanwhile, the maximum subsidence of the residential building was $75 \mathrm{~mm}$, the maximum surface horizontal deformation was $0.85 \mathrm{~mm} / \mathrm{m}$, and the maximum inclination was $-1.7 \mathrm{~mm} / \mathrm{m}$. As for the water pipe station, its maximum values of subsidence, surface horizontal deformation, and inclination were $110 \mathrm{~mm}, 1.1 \mathrm{~mm} / \mathrm{m}$, and 2.0 , respectively. The major part of the village was within level I of damage, the remaining part reaching level II. Considering the protection level of surface structures and the control requirements of reinforcement standards, the strip mining method greatly affected the safety of surface buildings and structures. To ensure the stability of surface residential buildings, signal towers, and high-voltage line towers, scheme I of RMCPB is recommended to achieve safe mining under the buildings. In this 
TABLE 4: Integrated benefit analysis.

\begin{tabular}{lccccc}
\hline \multirow{2}{*}{$\begin{array}{c}\text { Method } \\
\end{array}$} & Mined coal reserves (mln ton) & Cost (USD/ton) & Profit (USD/ton) & Total profit (mln USD) & $\begin{array}{c}\text { Environmental benefits } \\
\text { Gangue treatment (mln ton) }\end{array}$ \\
\hline RMCPB & 0.46 & 64.50 & 10.50 & 4.83 & 0.66 \\
Strip mining & 0.24 & 52.50 & 22.50 & 5.40 & 0.00 \\
\hline
\end{tabular}

scheme, coal resources under buildings can be maximally utilized, and a large volume of abandoned waste gangue can be backfilled into the goaf to control surface subsidence. This scheme allows one to achieve economical, ecological, and environmental benefits listed in Table 4, in comparison to strip mining.

It can be seen in Table 4 that, after the RMCPB of the mining area under study, the output of coal resources was 0.46 million tons and exceeds that of strip mining by 0.22 million tons. After considering the backfilling system, equipment, and personnel costs, the total profit in RMCPB was $4.83 \mathrm{mln}$ USD, being only by $10.5 \%$ less than that in strip mining ( $5.4 \mathrm{mln}$ USD). The main advantage of the former method over the latter one was that it made possible the underground treatment of 0.66 million tons of waste gangue. The integrated analysis of mined coal resources, mine service life, and environmental protection, revealed that the $\mathrm{RMCPB}$ application to the case study mining area comprehensively combined economic and environmental benefits.

\section{Conclusions}

In this study, the mining geological conditions of the case study coal mine, its type, construction, and buildings' protection standards were analyzed. The RMCPB and strip mining methods were applied to extract residual coal resources under buildings. The prediction model of the probability integration method was elaborated to study the surface subsidence and deformation via both mining methods. The research results show that the maximum subsidence of the surface above the mining area with $\mathrm{RMCPB}$ was $170 \mathrm{~mm}$. The maximum horizontal movement of the ground surface was $55 \mathrm{~mm}$, and the maximum horizontal deformation was $1.2 \mathrm{~mm} / \mathrm{m}$. The maximum inclination and curvature was $1.8 \mathrm{~mm} / \mathrm{m}$ and $0.04 \mathrm{~mm} / \mathrm{m}^{2}$, respectively. In case of strip mining, the maximum subsidence of the surface above the mining area was $230 \mathrm{~mm}$. The maximum values of horizontal movement, horizontal deformation, inclination, and curvature were $110 \mathrm{~mm}, 0.40 \mathrm{~mm} / \mathrm{m}, 0.35 \mathrm{~mm} / \mathrm{m}$, and $0.04 \mathrm{~mm} / \mathrm{m}^{2}$. To ensure the stability of surface buildings, RMCPB via scheme I is recommended to achieve safe mining under the buildings. In this scheme, coal resources under buildings can be maximally utilized, and a large volume of abandoned waste gangue can be backfilled into the goaf to control surface subsidence. The proposed method combines economic and environmental benefits, which make it lucrative for wide implementation in similar mining areas below industrial sites with surface buildings.

\section{Data Availability}

The data used to support the findings of this study are available from the corresponding author upon request.

\section{Conflicts of Interest}

The authors declare that they have no conflicts of interest.

\section{Acknowledgments}

The authors appreciate the financial support of this work provided by China Postdoctoral Science Foundation (2020M671650).

\section{References}

[1] M. Li, J. Zhang, and R. Gao, "Compression characteristics of solid wastes as backfill materials," Advances in Materials Science and Engineering, vol. 2016, Article ID 2496194, 7 pages, 2016.

[2] D. Z. Kong, S. J. Pu, Z. H. Cheng, G. Y. Wu, and Y. Liu, "Coordinated deformation mechanism of the top coal and filling body of gob-side entry retaining in a fully mechanized caving face," International Journal of Geomechanics, vol. 21, no. 4, p. 04021030, 2021.

[3] J. Lou, F. Gao, J. Yang et al., "Characteristics of evolution of mining-induced stress field in the longwall panel: insights from physical modeling," International Journal of Coal Science \& Technology, 2021.

[4] T. Jirina and S. Jan, "Reduction of surface subsidence risk by fly ash exploitation as filling material in deep mining areas," Natural Hazards, vol. 53, no. 2, pp. 251-258, 2010.

[5] G. Fan, D. Zhang, and X. Wang, "Reduction and utilization of coal mine waste rock in China: a case study in Tiefa coalfield," Resources, Conservation and Recycling, vol. 83, pp. 24-33, 2014.

[6] J. Zhang, H. Jiang, X. Deng, and F. Ju, "Prediction of the height of the water-conducting zone above the mined panel in solid backfill mining, mine water and the environment," Mine Water Environment, vol. 33, no. 4, pp. 317-326, 2014.

[7] M. Li, J. X. Zhang, Y. L. Huang, and N. Zhou, "Effects of particle size of crushed gangue backfill materials on surface subsidence and its application under buildings," Environment Earth Science, vol. 76, no. 17, p. 603, 2017.

[8] S. S. Brake, H. K. Dannelly, and K. A. Connors, "Controls on the nature and distribution of an alga in coal mine-waste environments and its potential impact on water quality," Environmental Geology, vol. 40, no. 4-5, pp. 458-469, 2001.

[9] E. K. Skierszkan, K. U. Mayer, D. Weis, and R. D. Beckie, "Molybdenum and zinc stable isotope variation in mining waste rock drainage and waste rock at the Antamina mine, Peru," Science of the Total Environment, vol. 550, pp. 103-113, 2016. 
[10] X. Y. Yu, X. W. Mao, N. Lu, and Q. Guo, "Research on strip mining with large mining depth under dense buildings," Coal Mining Technology, vol. 23, no. 6, pp. 71-76, 2018.

[11] J. X. Zhang, Q. Sun, A. Fourie, F. Ju, and X. J. Dong, "Risk assessment and prevention of surface subsidence in deep multiple coal seam mining under dense above-ground buildings: case study," Human Ecological Risk Assessment, vol. 25, no. 4, pp. 1-15, 2018.

[12] H. Teng, J. L. Xu, D. Y. Xuan, and B. L. Wang, "Surface subsidence characteristics of grout injection into overburden: case study of Yuandian No. 2 coalmine, China," Environment Earth Science, vol. 75, no. 6, pp. 1-11, 2016.

[13] H. Liu, K. Z. Deng, C. G. He, C. D. Sun, Z. L. Dong, and A. B. Zhang, "Surface subsidence law of filling with superhigh-water material and skip mining," Journal of China Coal Society, vol. 38, no. z2, pp. 272-276, 2013.

[14] H. Liu, J. Zhang, B. Li et al., "Environmental behavior of construction and demolition waste as recycled aggregates for backfilling in mines: leaching toxicity and surface subsidence studies," Journal of Hazardous Materials, vol. 389, p. 121870, 2020.

[15] H. Jiang, M. Fall, E. Yilmaz, Y. Li, and L. Yang, "Effect of mineral admixtures on flow properties of fresh cemented paste backfill: assessment of time dependency and thixotropy," Powder Technology, vol. 372, no. 15, pp. 258-266, 2020.

[16] State Bureau of Coal Industry, Regulations of Coal Pillar Design and Extraction for Buildings, Water Bodies, Railways, Main Shafts and Roadways, Coal Industry Press, Beijing, China, 2000.

[17] X. J. Deng, Ground Control Mechanism of Mining ExtraThickcoal Seam Using Upward Slicing Longwall-Roadway Cemented Backfilling Technology, Ph.D. thesis, China University of Mining and Technology, Xuzhou, China, 2017.

[18] X. J. Deng, B. Klein, J. X. Zhang, D. Hallbom, and B. De Wit, "Time-dependent rheological behaviour of cemented backfill mixture," International Journal of Mining, Reclamation and Environment, vol. 32, no. 3, pp. 145-162, 2018.

[19] H. Liu, J. Zhang, W. Zhang, F. Gao, H. Yan, and T. An, "Experimental investigation of perceptual characteristics of functional cemented backfilling materials in coal mines," Minerals, vol. 9, no. 1, pp. 55-70, 2019.

[20] J. Li, J. Zhang, Y. Huang, Q. Zhang, and J. Xu, "An investigation of surface deformation after fully mechanized, solid back fill mining," International Journal of Mining Science and Technology, vol. 22, no. 4, pp. 453-457, 2012.

[21] G.-L. Guo, X.-J. Zhu, J.-F. Zha, and Q. Wang, "Subsidence prediction method based on equivalent mining height theory for solid backfilling mining," Transactions of Nonferrous Metals Society of China, vol. 24, no. 10, pp. 3302-3308, 2014.

[22] J. X. Zhang, Study on Strata Movement Controlling by Raw Waste Backfilling with Fully-Mechanized Coal Mining Technology and Its Engineering Applications, Ph.D. thesis, China University of Mining and Technology, Xuzhou, China, 2008.

[23] J. F. Lou and C. M. Branch, "Research and application of hydraulic support simulation system for large-scale working face physical modeling experiment," Coal Science and Technology, vol. 46, no. 5, pp. 67-73+80, 2018. 